\title{
18 Yaş Altı İki Farklı Yaş Grubunda Mobil Teknoloji ve Bilgisayar Kullanım Alışkanlıkları ile Postürlerinin Karşılaştırılması
}

\section{Comparison of Mobile Technology and Computer Usage Habits and Postures in Two Different Age Groups Under 18}

\author{
Arzu Razak Özdinçler ${ }^{1 *}$, Ezgi Türkmen ${ }^{2}$, Tuğba Çivi Karaaslan ${ }^{3}$, Güzin Kaya Aytutuldu ${ }^{4}$, Sezen Karabörklü Argut ${ }^{3}$

\footnotetext{
${ }^{1}$ Biruni Üniversitesi, Sağlık Bilimleri Fakültesi, Fizyoterapi ve Rehabilitasyon Bölümü, İstanbul, Türkiye.

2 İstanbul Üniversitesi-Cerrahpaşa, Lisansüstü Eğitim Enstitüsü, Fizyoterapi ve Rehabilitasyon Anabilim Dalı, İstanbul, Türkiye. Türkiye.

${ }^{4}$ Yeditepe Üniversitesi, Sağlık Bilimleri Fakültesi, Fizyoterapi ve Rehabilitasyon Bölümü, İstanbul, Türkiye.
} \\ 3 İstanbul Üniversitesi-Cerrahpaşa, Sağlık Bilimleri Fakültesi, Fizyoterapi ve Rehabilitasyon Bölümü, İstanbul,
}

e-mail: arzuozdincler@hotmail.com, ezgi.turkmen.49@hotmail.com,tugbacivi@ hotmail.com, gznkaya@hotmail.com, sezen.karaborklu@istanbul.edu.tr.

ORCID: 0000-0003-1783-3992

ORCID: 0000-0002-9767-601X

ORCID: 0000-0002-8237-9290

ORCID: 0000-0002-0192-9861

ORCID: 0000-0002-7466-8105

*Sorumlu yazar/ Corresponding Author: Arzu Razak Özdinçler

Gönderim Tarihi / Received: 10.11.2020

Kabul Tarihi / Accepted: 9.09.2021

DOI: $10.34087 /$ cbusbed. 824038

\section{Öz}

Giriş ve Amaç: Günümüzde artan teknoloji kullanımı nedeniyle gelişim çağındaki bireylerin teknolojik cihazlar ve internette geçirdiği zamanın kontrolsüzlüğü postüral rahatsızlıklara sebep olabilmektedir. Bu çalışmanın amacı; 18 yaş altı iki farklı yaş grubunda ki bireylerin mobil teknoloji ve bilgisayar kullanım alışkanlıklarını incelemek ve postürlerini karşılaştırmaktır.

Gereç ve Yöntemler: Çalışmaya 7-12 yaş grubu (Grup 1, n=48) ve 12-18 yaş grubundan (Grup 2, n=40) toplam 88 sağlıklı birey dahil edildi. Değerlendirmede katılımcıların sosyo-demografik özellikleri, vücut kütle indeksleri ile bel çevresi ölçümlerini içeren ve mobil teknoloji ve bilgisayar kullanım özelliklerini sorgulayan bir araştırma anket formu kullanıldı. Katılımcılar ayrıca New York Postür Değerlendirme Testi (NYPDT) ile değerlendirildi.

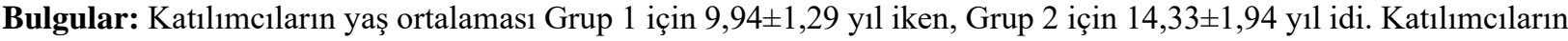
bilgisayarla en çok vakit geçirdikleri aktivite; Grup 1 için oyun oynamak (\%54,2), Grup 2 için ise müzik dinlemek (\%60) idi. Katılımcıların cep telefonunu en çok hangi aktivite için kullandıkları incelendiğinde; Grup 1'in oyun oynamak $(\% 37,5)$, Grup 2'nin ise internette serbest zaman geçirmek $(\% 77,5)$ amaciyla kullandığ görüldü. İki grup arasında NYPDT skoru açısından Grup 1 lehine anlamlı bir fark olduğu belirlendi ( $\mathrm{p}=0,0001)$.

Sonuç: Gelişim dönemindeki bireylerin teknoloji kullanım özellikleri ve postüral düzgünlükleri incelendiğinde, artan yaş ile teknoloji kullanımının da arttığını görmekteyiz. Daha büyük yaş grubundaki bireylerin teknolojik cihazları internet kullanımı gibi sebeplerle ve daha uzun sürelerle kullanmalarının postürlerini olumsuz etkilediğini düşünmekteyiz.

Anahtar kelimeler: İnternet, Onsekiz yaş altı, Postür, Teknoloji.

\section{Abstract}

Objective: Nowadays, due to the increasing use of technology, uncontrolled use of technological devices and time spent on the internet can cause postural disturbances in individuals on developmental age. The aim of this study was to examine the technology usage characteristics of individuals aged 18 and under and to compare these characteristics and postural alignment in different age groups. 
Materials and Methods: A total of 88 healthy individuals from 7-12 age group (Group 1, n=48) and 12-18 age group (Group 2, n=40) were included in the study. Socio-demographic characteristics of the participants were questioned with "Patient Evaluation Form". Participants were also evaluated with "The New York Posture Rating" (NYPR).

Results: The mean age of the participants was $9.94 \pm 1.29$ years for Group 1 and $14.33 \pm 1.94$ years for Group 2 . The activity that participants had the most time with computer; playing games in Group 1 (54.2\%) and listening to music in Group 2 (60\%). Participants most commonly used their mobile phone; playing games in Group 1 (37.5\%) and spending free time on the Internet for Group $2(77.5 \%)$. There was a significant difference between groups in favor of Group 1 for NYPR score $(\mathrm{p}=0.0001)$.

Conclusion: When the technology usage characteristics and the postural alignment of the individuals on developmental age are examined, we see that technology usage increases with increasing age. We think that the use of technological devices by adolescents for long periods of time due to internet usage or etc adversely affects their posture.

Keywords: Internet, Posture, Technology, Under eighteen years.

\section{Giriș}

Postür, vücudu oluşturan segmentlerin birbirleriyle uyumlu dizilimde oluşturdukları en iyi pozisyon olarak tanımlanmaktadır [1]. Postür, insan vücudunun pozisyonuna ve onun uzaydaki oryantasyonuna bağlıdır. Statik veya dinamik bir postürün sağlanmasında öncelikli etmenlerden biri olan kas kuvveti, vücudun yerçekimene karşı dik tutulmasını sağlayan antigravite kasları sayesinde elde edilir [2]. Irk, cinsiyet, egzersiz alışkanlığı, kas-iskelet sistemi problemleri, eklemlerin normal yerleşim açılarında bozukluklar, meslek ve uğraşılar, beslenme, uyku düzeni, psikolojik durum, hijyen, yorgunluk, sosyo-ekonomik durum, zamanın modası ve emosyonel durumlar postürü etkilemektedir [1]. Genç bireylerin teknolojiyi kullanırken ergonomik olmayan sandalyelerde uzun süre oturması yada uygun olmayan pozisyonlarda olmaları omurga sağlığını ve postüral gelişimi olumsuz yönde etkilemektedir [3].Günlük yaşamımızda olmazsa olmaz hale gelen teknoloji kullanımı, her geçen gün hızla artarak yaşantımızın önemli bir parçasını oluşturmaktadır. Toplum altyapısını oluşturan genç bireyler, günlük hayatı kolaylaştıran ve hızlandıran teknolojik cihaz kullanımı konusunda en büyük orana sahiptir [4]. Son yıllarda hızla artış gösteren internet oyunları, özellikle çocuk ve ergenler arasında oldukça yaygındır. Ruhsal Bozuklukların Tanısal ve Sayımsal El Kitabı-5. Baskısı'nda (DSM-5) “internet oyunu oynama bozukluğu" (İOOB), aşırı derecede oyun oynama ve çekilme, tolerans ve kontrol kaybı belirtileri ile birlikte, ilişki, iş veya eğitim olanaklarının internet oyunları sebebiyle tehlikeye atıldığı veya kaybedildiği durum olarak tanımlanmaktadır [5].

Erken yaşta uzun süreli bilgisayar kullanımının meydana getirdiği fizyolojik ve psikolojik problemler günümüzde ivme kazanmaktadır. Bu problemlerin başında; kişilerin postüründe ve kas-iskelet sisteminde görülen bozukluklar gelmektedir [6].

Günümüzde teknolojik cihazlarla ve internette geçirilen sürenin kontrolsüzlüğünün, gelişim çağındaki bireylerin kas-iskelet sistemi gelişimlerini olumsuz etkilemesi sebebiyle yetersiz fiziksel aktivite ve kötü postüral pozisyonlarda uzun süre kalmanın postüral düzgünlükte azalmaya neden olabilmektedir.Uzun süreli oturmanın lumbal bölge eklem hareket açıklığı ve spinal yüksekliğin azalmasına neden olduğu bildirilmiştir ve omurgada meydana gelen esneklik kayb1 intervertebral disk dehidrasyonundan kaynaklanabileceği savunulmuştur [7].
Bununla birlikte sandalyede oturma gibi uzun süreli statik postürün iliopsoas kasında adaptif bir kısalığın gelişmesine ve esnekliğinin azalmasına neden olabileceği belirtilmiştir [8]. Jorgensson iliopsoas kası kısaldığında gövdenin karşı tarafa lateral fleksiyonunu ve aynı tarafa doğru gövde rotasyonunu sinırlandıracağını ve omurgada meydana gelen bu asimetri nedeniyle skolyoza zemin hazırlayacağını ifade etmiştir. Bunun nedeni olarak, iliopsoas kasının yalnızca kalça ekleminde değil aynı zamanda lumbar omurga, postür ve intervertebral hareketlilik üzerinde de etkilere sahip olduğunu gösterilmiştir [9]. .İliopsoas kasında meydana gelen kısalığın gluteal kasların resiprokal inhibisyon yoluyla fonksiyonel olarak zayıflamasına neden olduğu ve değişmiş kuvvet çifti ilişkisi sonucunda artmış lumbal lordoz, artmış anterior pelvik tilt ve kalça fleksiyonu ile karakterize olan ve "alt çapraz sendromu" olarak bilinen kas-iskelet sistemi problemine neden olduğu bildirilmiştir [8]. İliopsoas kasında meydana gelen esneklik kaybı sonrasında ortaya çıkan "alt çapraz sendrom" büyüme çağındaki çocuklarda oldukça s1k görülen, beraberinde birçok probleme neden olan, tedavi maliyeti yüksek, yaşam kalitesini azaltan ve fonksiyonel skolyoz olarak adlandırılan omurga probleminin gelişmesine zemin hazırlayabilir. Kas imbalansı sonrasında meydana gelen fonksiyonel skolyoz erken dönemde belirlendiğinde ilerlemesi kontrol altına alınabilecek hatta ortadan kaldırılabilecek bir omurga problemidir [8,9].

$\mathrm{Bu}$ çalışmanın amacı; 18 yaş altı iki farklı yaş grubundaki bireylerin mobil teknoloji ve bilgisayar kullanım alışkanlıklarını incelemek ve postürlerini karşılaştırmaktır.

\section{Materyal ve Metot}

Çalışmamız bir değerlendirme araştırması olup Haziran 2018-Eylül 2018 tarihleri arasında, İstanbul sınırları içerisinde ulaşabildiğimiz 314 yaş grubumuza uygun çocuk ile planlandı Ailelerinin izniyle ve "Bilgilendirilmiş Gönüllü Onam Formu" ile çalışmaya katılmayı kabul edenler çocukların tamamı çalışmaya dahil edildi. Araştırma Helsinki Bildirgesi'ne uygun olarak yürütüldü. Araştırmaya alınan gönüllülere çalışmanın amacı hakkında bilgi verildi. Bilgilendirilmiş onam formunda "Çocuğumun araştırmaya katılmasını kabul ediyorum." kutucuğunu işaretleyen katılımcılar çalışmaya alındı. 7-12 yaş grubu (Grup 1, n=48) ve 12-18 yaş grubu (Grup 2, $\mathrm{n}=40)$ olmak üzere toplam 88 sağlıklı birey ile 
gerçekleştirildi. Sağlıklı oldukları konusunda aile bildirimine göre hareket edildi. Kronik hastalığı olmamak, engelli olmamak, örgün eğitime devam ediyor olmak ve çalışmaya gönüllü olmak dahil edilme kriterlerimizdi.

\subsection{Değerlendirmeler}

Çalışmamızda katılımcıların sosyodemografik özellikleri, vücut kütle indeksleri ve bel çevresi ölçümleri ile teknoloji kullanım özelliklerini sorgulayan bir araştırma anket formu kullanıldı. Katılımcıların bilgi iletişim teknolojilerinden hangilerini (cep telefonu, notebook, tablet, masaüstü bilgisayar) ne kadar süre ile ve ne amaçla kullandıkları sorgulandı. $\mathrm{Bu}$ kısım kişilerin kendilerince dolduruldu. Katılımcılar ayrıca New York Postür Değerlendirme Testi (NYPDT) ile fizyoterapistler tarafindan değerlendirildi. Anket bilgileri bir araştırmacıda (ARÖ) toplandı ve postür değerlendirmesi yapan araştırmacılar bu bilgilere kördü. New York Postür Değerlendirme Testi ile; vücudun baş, boyun, omuz, sırt, bel, kalça ve ayak bileği dahil 13 ayrı kısmındaki postür değişiklikler gözlemlenir. Sonuçlara göre kişi "düzgün" postüre sahipse kişiye " 5 ", postürü "orta" derecede bozulmuş ise "3", "ciddi" bir bozulma varsa "1" puan verilir. Test sonucunda alınan toplam puan 13-65 arasında değişiklik göstermektedir. Bu test için geliştirilmiş standart değerlendirme kriterleri toplam puan $\geq 45$ ise "çok iyi", 40-44 ise "iyi", 30-39 ise "orta", 20- 29 ise "zayıf" ve $\leq 19$ ise "kötü" olarak belirlenmiştir [10].

\subsection{Istatistiksel Analiz}

Çalışma verilerinin istatistiksel analizi için "Statistical Package for Social Sciences" (SPSS) Version 20.0 (SPSS inc., Chicago, IL, ABD) istatistik programı kullanıldı. Verilerin normal dağılıma uygunluğu Shapiro-Wilk test ile; bağımsız örneklemler arasındaki ilişki Independent Sample T-Test kullanılarak analiz edildi ve tüm analizlerde $\mathrm{p}<0,05$ değeri istatistiksel olarak anlamlı kabul edildi.

\section{Bulgular ve Tartışma}

\subsection{Bulgular}

Çalışma kapsamında 18 yaş ve altı 88 sağlıklı ve çalışmaya katılmaya gönüllü birey değerlendirildi. Grup 1'in yaş ortalaması 9,94 $\pm 1,29$ yıl iken, Grup 2'nin yaş ortalaması $14,33 \pm 1,94$ y1l idi. Grup 1'in \%41,7'sini $(n=20) \mathrm{k1z}$ çocukları oluşturmakta iken Grup 2'de bu oran \%40 $(n=16)$ idi. Sosyodemografik veriler bakımından karşılaştırıldığında grupların benzer özelliklerde olduğu görüldü $\quad(p>0,05)$. Katılımcıların sosyo-demografik özellikleri Tablo 1'de gösterilmiştir.

Tablo 1. Katılımcıların Sosyo-Demografik Özellikleri

\begin{tabular}{|l|c|c|}
\hline & $\begin{array}{c}\text { Grup I } \\
\mathbf{n : 4 8} \\
\text { Ort } \pm \text { SS }\end{array}$ & $\begin{array}{c}\text { Grup II } \\
\mathbf{n : 4 0} \\
\text { Ort } \pm \text { SS }\end{array}$ \\
\hline Yaş (yıl) & $9,94 \pm 1,29$ & $14,33 \pm 1,94$ \\
\hline VKİ (kg/cm ${ }^{2}$ ) & $17,63 \pm 2,68$ & $20,94 \pm 2,97$ \\
\hline Bel Çevresi(cm) & $62,04 \pm 9,73$ & $71,71 \pm 10,18$ \\
\hline
\end{tabular}

Ort: Ortalama, SS: Standart Sapma, VKİ: Vücut Kütle İndeksi
Grupların bilişim teknolojileriyle geçirdikleri vakit incelendiğinde, Grup 1'in gün içerisinde en çok süreyi tablet ve cep telefonu ile geçirdiği; Grup 2'nin ise en çok süreyi cep telefonuna ayırdığı görüldü. Gün içindeki ortalama internet kullanım sürelerine bakılacak olduğunda,

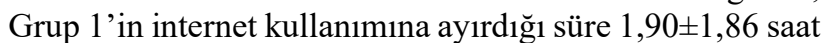
iken; Grup 2 için bu süre 3,75 $\pm 2,83$ saat idi.

Katılımcıların bilgisayarı en çok hangi aktivite için kullandıkları incelediğinde; Grup 1'in en çok oyun oynamak $(\% 54,2)$, Grup 2'nin ise müzik dinlemek (\%60) amacıyla kullandıkları görüldü.

Katılımcıların cep telefonuyla en çok vakit geçirdikleri aktivite ise; Grup 1 için oyun oynamak iken $(\% 37,5)$ Grup 2 için ise internette serbest zaman geçirmek $(\% 77,5)$ idi.

Yıl bazında incelediğinde, tablet dışındaki tüm teknolojik cihazların kullanım süreleri açısından gruplar arasında anlamlı farklılık olduğu görüldü $(\mathrm{p}<0,05)$.

Saat bazında ise yalnızca cep telefonu ve internet kullanımı açısından gruplar arasında anlamlı farklılık vardı $(p<0,05)$. Katılımcıların farklı teknolojik cihazları kullanım özellikleri ve NYPDT skorları Tablo 2'de gösterilmiştir.

İki grup arasında New York Postür Değerlendirme Testi skoru açısından Grup 1 lehine anlamlı bir fark olduğu belirlendi ( $\mathrm{p}=0,0001)$.

3.2. Tartışma

Teknolojinin hızla gelişmesiyle beraber yaşam şeklimizin de bu duruma uyum sağlaması kaçınılmazdır. Günümüzde bireylerin cep telefonu, tablet ve bilgisayarda geçirdikleri zamanın artmasıyla, fiziksel olarak inaktif bir yaşam tarzı benimsenmektedir. Bu durum gelişim çağındaki bireylerin fiziksel ve duygusal gelişiminde olumsuz bir rol oynayabilmektedir. Yapılan araştırmalar, okul çağındaki bireylerin serbest zamanlarının çoğunu teknoloji kullanımıyla geçirdiğini ve fiziksel aktivite düzeylerinin oldukça yetersiz olduğunu, bu durumun da çeşitli muskuloskeletal problemlere sebep olabildiğini bildirmektedir [11,12]. Çalışmamızda literatüre paralel şekilde çocukluk ve ergenlik dönemindeki bireylerin teknoloji kullanım özellikleri incelendiğinde, ilerleyen yaşla beraber adölesan yaş grubu olarak tanımlayabileceğimiz bireylerde teknoloji kullanımının arttığını ve bu durumun bireylerin postürlerini olumsuz etkilediğini görmekteyiz.

7-12 yaş grubu ile 12-18 yaş grubundan bireyleri karşılaştırdığımız çalışmamızda, iki grup arasında New York Postür Değerlendirme Testi ile değerlendirilen postüral düzgünlük açısından, teknoloji kullanımının daha yoğun olduğu daha büyük yaş grubundaki bireylerin aleyhine bir fark olduğu görülmektedir. $\mathrm{Bu}$ durum bize artmış teknoloji kullanımı nedeniyle azalan fiziksel aktivite ve postüral kontrolün, postüral düzgünlüğü olumsuz etkilediğini göstermektedir. Gruplar arasında Grup 2 lehine anlamlı düzeyde farklı olarak yüksek çıkan cep telefonu kullanım yılı çok doğaldır. Ülkemizde çocukların kendine özel cep telefonu alma yaşı artık 7 yaşlarına kadar düşmüş olsa da 12-18 aralığındaki çocukların daha uzun zamandır bir cep telefonuna sahip oldukları bir gerçektir. Ayrıca yine Grup 2 de daha yüksek çıkan ve anlamlı düzeyde farklı olan internet kullanım saati 
Tablo 2. Farklı Teknolojik Cihazların Kullanım Süreleri

\begin{tabular}{|c|c|c|c|}
\hline $\mathrm{N}: 88$ & $\begin{array}{c}\text { Grup I } \\
\text { n:48 } \\
\text { Ort } \pm \text { SS }\end{array}$ & $\begin{array}{c}\text { Grup II } \\
\text { n:40 } \\
\text { Ort } \pm \text { SS }\end{array}$ & $p$ değeri \\
\hline \multicolumn{4}{|l|}{ Yll } \\
\hline Cep Telefonu & $0,97 \pm 1,17$ & $2,46 \pm 2,30$ & 0,0001 \\
\hline Notebook & $0,62 \pm 1,20$ & $1,95 \pm 3,04$ & 0,007 \\
\hline Tablet & $1,97 \pm 1,74$ & $2,09 \pm 2,22$ & 0,788 \\
\hline Masaüstü Bilgisayar & $1,33 \pm 1,80$ & $2,47 \pm 3,07$ & 0,033 \\
\hline İnternet & $2,65 \pm 1,80$ & $4,47 \pm 2,81$ & 0,0001 \\
\hline \multicolumn{4}{|l|}{ Saat } \\
\hline Cep Telefonu & $1,06 \pm 1,84$ & $3,07 \pm 2,56$ & 0,0001 \\
\hline Notebook & $0,39 \pm 0,67$ & $0,62 \pm 0,93$ & 0,188 \\
\hline Tablet & $1,09 \pm 1,19$ & $0,63 \pm 0,93$ & 0,054 \\
\hline Masaüstü Bilgisayar & $0,42 \pm 0,69$ & $0,67 \pm 1,05$ & 0,191 \\
\hline İnternet & $1,90 \pm 1,86$ & $3,75 \pm 2,83$ & 0,0001 \\
\hline NYPD & $59,92 \pm 3,89$ & $53,78 \pm 8,54$ & 0,0001 \\
\hline
\end{tabular}

NYPDT: New York Postür Değerlendirme Testi. Ort: Ortalama, SS: Standart Sapma

de anlaşılabilir bir durumdur.12-18 yaş grubunun internet kotasının daha yüksek olabileceği düşünülmüştür.

Ayrıca 7-12 yaş grubu çocuklara aileleri tarafindan internet kullanımı izni daha kontrollü olarak verilmektedir. Ülkemizde 2012 yılında yapılan çalışmada da çalışmamıza benzer şekilde 7-11 yaş aralığındaki bireylerin çanta taşıma, bilgisayar kullanma alışkanlıkları ve postürleri değerlendirilmiş; bu bireylerin $\% 80,5$ 'inin gün içinde bilgisayar kullandığı ve \%70'inin günde en az 1-2 saat bilgisayar karşısında zaman geçirdiği ifade edilmiştir [13]. Rideout ve arkadaşlarının yaptığ 1 başka bir çalışmada, 2011 yılında 0-8 yaş grubu çocukların \%52'sinin teknolojik cihaz kullandığ1, kullanım oranının 2013 yılında ise $\% 75$ düzeyine kadar çıktığı bildirilmiştir [14]. Yine 2002 yılında yapılan bir çalışmada 8-18 yaş arası bireylerin günlük bilgisayar kullanımının çalışmamıza benzer şekilde 101 dakika olduğu görülmüştür [15].

"İnternet bağımlılığg” terimi ilk kez Ivan Goldberg tarafından 1996 yılında patolojik internet kullanımını tanımlamak için önerilen bir terimdir [16]. Amerikan Psikiyatri Birliği tarafından geliştirilen ve 2013 yılında yayınlanan Ruhsal Bozuklukların Tanısal ve Sayımsal El Kitabı-5 (DSM-5)'te "ileri araştırma gereken durumlar" başlığı altında yer alan "internet oyunu oynama bozukluğu”tanımlanmıştır. İnternet bağımlılığının yaygınlığı üzerine olan bilgiler sınırlı olsa da bugüne kadar yapılan çalışmalar internet bağımlılığı yaygınlığının \% $\quad 0,3$ ile $\% 38$ arasında değiştiğini göstermektedir [4,17,18].Tipik bir internet bağımlısının haftada 40-80 saat arasında bilgisayar başında kaldığı ve tek seferde hiç aralıksız 20 saate kadar bilgisayar başından kalkmayabileceği düşünüldüğünde kas iskelet sistemi sağlı̆̆ının yanı sıra kardiyorespiratuvar fonksiyonların da olumsuz etkilenmesi kaçınılmazdır. Bizim çalışmamızda tüm mobil teknoloji ve bilgisayar kullanım süreleri toplandığında bile haftada 5-6 saat gibi bir süre çıkmaktadır.

Çocuk ve ergenlerin bilgisayar kullanmaya erken yaşta başlamaları ve erişkinler için tasarlanan bilgisayar ve bilgisayar mobilyalarının kendileri için uygun boyutlarda olmaması nedeniyle yetişkinlere kıyasla daha yüksek risk altında olduğu bildirilmiştir[19].Bilgisayar kullanımının çocuk ve ergenlerde postural düzgünlüğü etkilediğini gösteren çalışmalar mevcuttur. Çocuklarda bilgisayar kullanımı ile kas-iskelet sistemi problemlerinin ilişkisinin araştırıldığı bir çalışmada ortaokul öğrencilerinin yaklaşık olarak \%50'sinin vücudunun en az bir bölgesinde kas-iskelet sistemi rahatsızlığı olduğu belirtilmiştir. Orta dereceden şiddetli rahatsızlık düzeyine göre sıralandığında en sik problem görülen bölgelerin boyun, bel ve omuzlar olduğu bildirilmesine rağmen altında yatan biyomekanik problem tanımlanmamıştır [20]. Araştırmacılar, kötü postürün 
uzun süre devam ettirilmesi sonucu görülebilecek muskuloskeletal problemlere erken dönemde müdahale edilmesi gerektiğini, erken dönemde kas-iskelet sistemi rahatsızlığı/ağrısı yaşayan çocukların, yaşamlarının ilerleyen dönemlerinde benzer rahatsızlıklara yatkın olduğunu göstermiştir [21].

2006 yllinda farklı sosyodemografik gruplardan adölesanların boyun/omuz, bel ve kol ağrısı prevalansı ve ağrı durumunun bilgisayar kullanımı, fiziksel aktivite, depresyon ve stres ile ilişkisinin incelendiği bir araştırmada 3485 adölesan değerlendirilmiştir [22]. İncelenen populasyonda boyun/omuz ağris1 prevalansının \%11.5, bel ağrısı prevalansının \%7.5 ve kol ağrıs1 prevalansının \%3.9 olduğu belirlenmiştir. Boyun/omuz ağrısı prevalansı ebeveynleri ayrı olan gençlerde daha yüksek bulunurken, bel ağrısı sıklığının da kızlar arasında daha yüksek olduğu görülmüştür. Bu çalışma muskuloskeletal ağrının adölesan bireyler arasında yaygın olduğunu ve depresyon ve stresle ilişkili olduğunu ancak bilgisayar kullanımı ve fiziksel aktivite ile ilişkili olmadığını ifade etmektedir. Bu durum teknolojik cihaz kullanım süresi ile muskuloskeletal ağrı şikayeti arasında her zaman korelasyon olmadığını göstermektedir. Ancak literatürün geneline bakıldığında artan teknolojik cihaz kullanım süresi ve ilişkili inaktivite ile kötü postürün, ilerleyen dönemlerde karşılaşılabilecek kas-iskelet sistemi rahatsızlığına/ağrısına zemin hazırladığını göstermektedir [23].

\section{Sonuç}

Ebeveynlerin çocuklarının teknoloji kullanım alışkanlıklarını optimal düzeye indirgemek, onların sağlığını, iyilik halini, sosyal/kişisel gelişimini ve akademik performansını olumsuz yönde etkileyebilecek geleneksel ve yeni teknolojik cihaz kullanımıyla ilgili sorunların farkında olmaları ve bunları ele almak için sağlık çalışanlarıyla iş birliği içinde bulunmaları gerekliliğine literatürde özellikle vurgu yapılmaktadır.

Gelişim dönemindeki bireylerin gerek kas-iskelet sağlığının korunmasında, gerek postüral düzgünlüklerinin sağlanabilmesi ve korunabilmesi amacıyla, gerekse psikolojik ve emosyonel iyilik halinin korunması ve sürdürülebilmesi amacıyla teknoloji kullanımının güvenli aralıklarla sınırlanması ve bireylerin postür farkındalığı ve fiziksel aktivitenin önemi konusunda erken yaşta bilgilendirilmesi gerektiği görüşündeyiz. Ayrıca bu çalışmanın tamamlanmasının ardından dünyada gelişen Covid-19 pandemisi nedeniyle 7-18 yaş grubu çocukların eğitimleri için online süreçlere geçilmesi ve bunun teknoloji kullanımını ve oturma süresini arttırması bu durumun olumlu yanlarının yan sıra uzun süreçte oluşabilecek olumsuz durumlardan korunabilmek için yeni çalışmalar yaparak toplumu bilinçlendirmek gerekmektedir.

\section{References}

1. Karacaoğlu, S, Kayapinar, FÇ, The Effect of Core Training on Posture, Academic Journal of Interdisciplinary Studies, 2015, 1 (14), 221-226.

2.Hrysomallix, C, Goodman, C, A review of resistance exercise and posture realignment, Journal of Strength and Conditioning Research, 2001, 15(3), 385-390.

3. Asyikin, N, Shamsul, B, et al., Neck, Shoulder, Upper and Lower
Back Pain and Associated Risk Factors Among Primary School Children in Malaysia, Journal of Medical Safety, 2, 37-47.

4. Söyler, S, Kaptanoğlu, AY, Sanal Uyuşturucu: İnternet, Gümüşhane Üniversitesi Sağllk Bilimleri Dergisi, 2018, 7(2), 37-46.

5. Irmak, A.Y, Erdoğan, S, Dijital Oyun Bağımlılığı Ölçeği Türkçe formunun geçerliliği ve güvenilirliği, Anatolian Journal of Psychiatry, 16(1), 10-18.

6. Kelly, G, Dockrell, S, et al., Computer use in school: its effect on posture and discomfort in schoolchildren, Work, 2009, 32(3), 321328.

7.Phimphasak, C, Swangnetr, M, et al., Effects of seated lumbar extension postures on spinal height and lumbar range of motion during prolonged sitting, Ergonomics, 2016, 59(1), 112-120.

8. Page, P, Frank, C, et al., Assessment and treatment of muscle imbalance: the Janda approach, Human kinetics, United States, 2010.

9. Jorgensson, A, The iliopsoas muscle and the lumbar spine, Australian Journal of Physiotherapy, 1993, 39(2), 125-132.

10. Magee, D, Assessment of posture, In: Magee D (ed), Orthopaedic Physical Assessmentt, 6th edn, MO: Saunders Elsevier, St. Louis, 2014, pp 1017-1052.

11. Wojtyła, B.P, Stawińska, W.B, et al., Assessing Physical Activity and Sedentary Lifestyle Behaviours for Children and Adolescents Living in a District Of Poland. What are The Key Determinants for İmproving Health? Annals of Agricultural and Environmental Medicine, 2014, 3 (21), 606-612.

12. Mustfaoglu, R, Yasaci, Z, The Negative Effects of Digital Game Playing on Children's Mental and Physical Health, Journal of Dependence, 2018, 19(3), 51-58.

13. Demir, Parlak, Y, Çırak, ve ark., İlkokul Çocuklarında Çanta Taşıma, Bilgisayar Kullanma Alışkanlığı ve Postür, Ankara Medical Journal, 2012,12(4), 182-187.

14. Rideout, V, Saphir, M, et al., Zero to eight children's media use in America. San Francisco, CA: A Common Sense Media Research Study, 2011, http://www.commonsensemedia.org, (accessed 31.03.2020)

15. Gillespie, R.M, The physical impact of computers and electronic game use on children and adolescents, a review of current literature, Work, 2002, 18, 249-259.

16. Goldberg's message 1996, Internet Addiction Support Group, Is There Truth in Jest? John Suler's The Psychology of Cyberspace, This article created Agust 1996, revised March 1998. http://users.rider.edu/ suler/psycyber/supportgp.html (Erişim tarihi: 31.03.2018).

17. Bozkurt, H, Şahin, S, ve ark., İnternet Bağımlılı̆̆ı: Güncel Bir Gözden Geçirme, Jounal of Contemporary Medicine, 2016, 6(3), 2352-47.

18. Barrero, M, Hedge, A, Computer environments for children: a review of design issues, Work, 2002, 18(3), 227-237.

19. Straker, L.M, O'Sullivan, P.B, et al., Computer use and habitual spinal posture in Australian adolescents. Public Health Repots, 2007, 122, 634-643.

20. Jacobs, K, Baker, N.A, The association between children's computer use and musculoskeletal discomfort, Work, 2002, 18(3), 221-26.

21. Jacobs, K, Hudak, S, et al., Computer-related posture and musculoskeletal discomfort in middle school students, Work, 2009, 32, 275-283.

22. Diepenmaat, A.C, van der Wal, M.F, et al., Neck/shoulder, low back, and arm pain in relation to computer use, physical activity, stress, and depression among Dutch adolescents, Pediatrics, 2006, 117(2), 41216.

23. Mustafaoğlu, R, Zirek, E, Yasacı, Z, Razak, Özdinçler, A, The negative effects of digital technology usage on children's development and health, Addicta: The Turkish Journal on Addictions, 2018, 5(2), 13-2.

http://edergi.cbu.edu.tr/ojs/index.php/cbusbed isimli yazarın CBU-SBED başlıklı eseri bu Creative Commons Alıntı-Gayriticari4.0 Uluslararası Lisansı ile lisanslanmıştır.

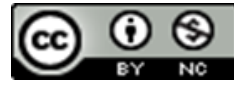

